\title{
Overdose of Cinnamon Barks Is the Cause of Poisoning in the Gediatric Patient: Case Report
}

\author{
Çiğdem Çolak ${ }^{1}$, Elif Elibol ${ }^{2}$, Türkan Demir ${ }^{3}$ and Bijen Kıvçak ${ }^{3}$ \\ 1. Tepecik Training and Research Hospital, Izmir 35180, Turkey \\ 2. Gaziemir Nevvar Salih İsgören Public Hospital, Izmir 35410, Turkey \\ 3. Department of Pharmacognosy, Faculty of Pharmacy, University of Ege, Izmir 35040, Turkey
}

\begin{abstract}
The use of herbal medicine has existed since the beginning of human history and interest in alternative medicine has increased in the last two decades. The use of these methods has increased in treatment. Drug interaction, toxicity, overdose and side effects are also increasing. There are many physiological changes that can affect the pharmacokinetics of herbal medicine in older people. Due to these changes, side effects and intoxications are observed in the geriatric patients. Cinnamon is spasmolytic activity, antibacterial, anti-inflammatory and antiseptic properties. The use of overdose is indicated to cause agitation, hypoglycemia, tachycardia, to increase the level of the used coumarin and abortion, tachycardia and arrhythmia in pregnancy. In this article, we report a case of woman. The patient is a 76-year-old female patient admitted to emergency service for nausea, cold sweating, palpitations, trembling. She has hypoglycemia, agitation and tachycardia. She poisoned cinnamon and honey mixture. In this study, the clinical and laboratory findings of the acute case due to depletion of overdose cinnamon (Cortex Cinnamomi cassiae) were presented in the light of literature information.
\end{abstract}

Key words: Geriatric patient, cinnamon, hypoglycemia, tachycardia, agitation.

\section{Background}

The strong relation that exists between plants and people is as old as human history. Thousands of years ago, humans realized the therapeutic effect of plants and used the plants for the prevention of diseases and the treatment of diseases. The ancient Egyptians, the Greeks and the Romans also used treatments with the applied plants, used the next generations and continuously enriched them. This development was based on trial and error. Nowadays, the usage among the people has been supported by scientific supports and the application of "Phytotherapy" has been started.

Cinnamon is the dried bark of some Cinnamomum (Lauraceae) species. There are two main varieties of cinnamon bark, namely Chinese cinnamon (Cortex Cinnamomi cassiae) and Ceylon cinnamon (Cortex Cinnamomi zeylanici). It has been used for thousands

Corresponding author: Çiğdem Çolak, MPharm, pharmacist, research field: phytotherapy. of years in terms of health. It is used in folk medicine with psychological problems, heart failure, influenza, cold, flu, anorexia, dyspepsia, diarrhea and intestinal worms. Cinnamon is laxative, gas extractor and antiseptic properties [1, 2]. Apart from that, it is also used as a spice and fragrance. Cinnamon contains 1-2\% volatile oil. The cinnamon oil obtained by distillation from its barks has a pleasant smell and taste; and contains cinnamic aldehyde and eugenol [3, 4]. The cinnamon bark also has the Cinchon Syrup (Sirupus cinnamomi) formulation registered to the Turkish Codex (T. K. 1954). The use of overdose is indicated to cause agitation, hypoglycemia, tachycardia, to increase the level of the used coumarin and abortion, tachycardia and arrhythmibarja in pregnancy $[5,6]$. Many recent studies have found that cinnamon is beneficial for alzheimer, diabetes, arthritis, atherosclerosis. However, more clinical research is needed to prove its usefulness against cancer, inflammatory diseases, cardioprotective and 
neurological disorders [7].

In this study, the clinical and laboratory findings of the acute case due to depletion of overdose cinnamonium (Cortex Cinnamomi cassiae) were presented in the light of literature information.

\section{Case Report}

F. I. who is 76-year-old female patient, was applied in case of panic with complaints of emergency nausea, cold sweating, palpitations, trembling. The patient was diagnosed with hypertension and insulin resistance.

She regularly uses 160/12.5 $\mathrm{mg}$ of valsartan/hydrochlorothiazide respectively. Her blood pressure was $140 / 90 \mathrm{mmHg}$, pulse $116 / \mathrm{min}$, respiratory rate $28 / \mathrm{min}$ and body temperature $38.7{ }^{\circ} \mathrm{C}$ on the physical examination. Neurological examination of the patient with agitation was normal. She has xerostomia. Chest X-ray was normal. Electrocardiography (ECG) had sinus tachycardia. In the full blood count, the patient's WBC (leukocytosis) was mildly elevated and her blood sugar was $68 \mathrm{mg} / \mathrm{dL}$. Besides, no pathology was observed in full urine tests and thyroid function tests. The patient was hospitalized and the tachycardia was monitored. Since agitation and tachycardia were present, $50 \mathrm{mg} \beta$-blockers were initiated. Intravenous $10 \%$ dextrose was made into $40 \mathrm{cc}$ pouches. Blood glucose levels were $80 \mathrm{mg} / \mathrm{dL}$ at 15 minutes later. After 1 hour, the pulse rate of the patient who had sinus tachycardia on ECG was 90/min. The patient was hydrated. On the second day of hospitalization, all the clinical findings returned normal and the patient was discharged.

\section{Results and Discussion}

Approximately, 70 percent of the herbal drug users continue to use another drug at the same time. The fact that the use of herbal remedies is usually unconsciously recommended by others and the herb is not mentioned in the anamnesis when the herb is being used. Moreover, the doctor is not informed and plant-drug interaction is ignored. The increased use of herbs for treatment increases drug interaction, toxicity, overdose and side effects in patients receiving conventional therapy. It is best to use in the consultation of the doctor and the pharmacist because the correct plant species are collected from the correct time and place as well as the selected plant for the treatment should be correct. However, in this regard, toxicity can be minimized and we can provide real benefits.

There are many physiological changes that may affect the herbal pharmacy and the pharmacokinetics of older people: for example, the reduction of the gastrointestinal motility and the surface of the absorbation, the reduction of total body water, the decrease in serum albumin depletion and protein binding, the decrease in biotransformation, the decrease in renal blood flow drug abstinence, the decrease in receptor sensitivity and the change in cellular response. Due to these factors, side effects due to herbal treatment and more intoxications are observed in the geriatric patients.

In 2007, Hlebowicz et al. [8] investigated in a cross-method study and conducted with 14 healthy volunteers. As a result, it was determined that the use of $6 \mathrm{~g}$ of drug per day lowered the level of satiety blood glucose, delayed gastric emptying without feeling of satiety. For these reasons, cinnamon bark further enhances the effect of soluble drugs in stomach. These side effects may also increase.

In a study by cortex cinnamomi monograph in ESCOP (European Scientific Cooperative on Phytotherapy), $180 \mathrm{mg} / \mathrm{mL}$ cinnamon bark extract made with benzene-methanol mixture was found to induce substrate binding spectroscopic interaction of microsomal cytochrome $\mathrm{p} 450$ in rat liver in vitro at a dose of $80 \mathrm{~mL}$. This suggests that cinnamon barks may cause toxic effects on the body and may interfere with medicines during prolonged and overdose.

In conclusion, it is the research results which are done to solve the problems and problems in the use of herbal medicines in the geriatric patients. And that there are serious problems with medicines. The 
interdisciplinary team work is necessary in identifying and solving the problems. And the cooperation between family physician, home care nurse, pharmacist and patient is importance especially in the understanding of the anamnesis.

\section{References}

[1] Pharmacopoeia Commission of People's Republic of China. 1992. Pharmacopoeia of the People's Republic of China (English ed.). Guangzhou: Guangdong Science and Technology Press.

[2] World Health Organization. Regional Office for the Western Pacific. 1989. Medicinal Plants in China. Manila 78-9.

[3] Bisset, N. G. 1994. Max Wichtl's Herbal Drugs \& Phytopharmaceuticals. CRC Press, 148-50.

[4] Bruneton, J. 1995. Pharmacognosy, Phytochemistry,
Medicinal Plants. Paris: Lavoisier, 451-3.

[5] Piccioni, A., and Badellino, E. 1989. "Pre-natal (Segment II) Toxicity Study of Cinnamic Aldehyde in the Sprague-Dawley Rat." Food Chem Toxicol 12: 781-6.

[6] Miller, K. G., Poole, C. F., and Chichila, T. M. P. 1995. "Solvent-Assisted Supercritical Fluid Extraction for the Isolation of Semivolatile Flavor Compounds from Cinnamons of Commerce and Their Separation by Series-Coupled Column Gas Chromatography." J. High Resol. Chromatograpy 18: 461-71.

[7] Ranasinghe, P., Pigera, S., Premakumara, S., Galappaththy, P., Constantine, G. R. and Katulanda, P. 2013. "Medicinal Properties of True Cinnamon (Cinnamomum Zeylanicum): A Systematic Review." BMC Complementary and Alternative Medicine 13: 275.

[8] Hlebowicz, J., Darwiche, G., Björgell, O., and Almér, L. O. 2007. "Effect of Cinnamon on Postprandial Blood Glucose, Gastric Emptying, and Satiety in Healthy Subjects." Am. J. Clin. Nutr. 85: 1552-6. 